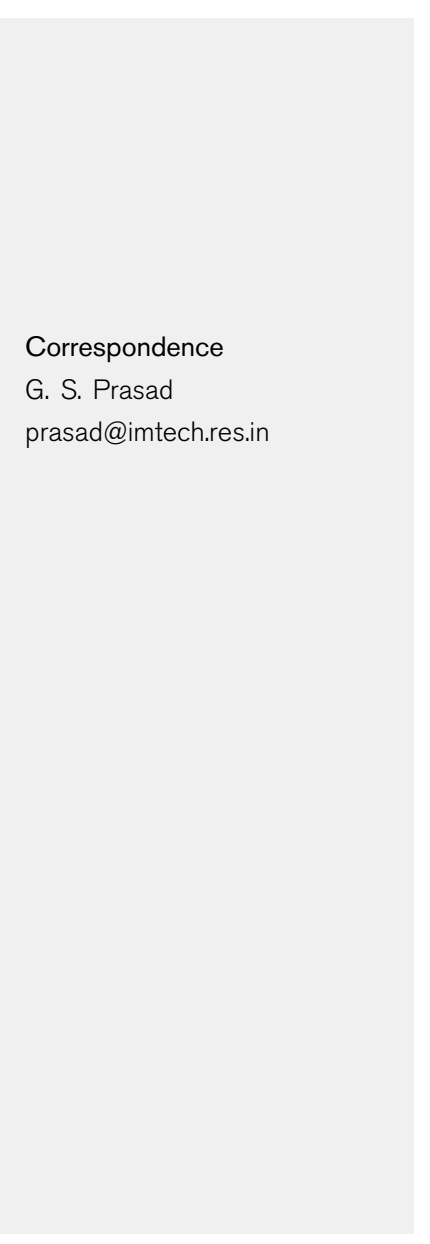

\section{Cryptococcus rajasthanensis sp. nov., an anamorphic yeast species related to Cryptococcus laurentii, isolated from Rajasthan, India}

\author{
Puja Saluja and G. S. Prasad
}

Microbial Type Culture Collection and Gene Bank (MTCC), Institute of Microbial Technology (IMTECH), Council of Scientific and Industrial Research (CSIR), Sector 39A, Chandigarh 160036, India

\begin{abstract}
Two novel anamorphic yeast strains $\left(S-15 L^{\top}\right.$ and $\left.3-C 1\right)$ were isolated from the inflorescences of plants collected in two different towns in Rajasthan State, India. Sequencing of the D1/D2 domains of the large-subunit (LSU) rDNA and the internal transcribed spacer (ITS) regions suggested they are strains of the same species. Phenotypic characteristics such as the absence of fermentation, the absence of sexual structures and ballistoconidia, the assimilation of myo-inositol and D-glucuronate, and positive Diazonium blue $B$ and urease reactions indicated that these strains belong to the genus Cryptococcus. The novel strains differed from Cryptococcus laurentii in six physiological tests and differed from other related species in more than six tests. A phylogenetic analysis of the sequences of the D1/D2 domains of the LSU rDNA and the ITS regions placed these strains in the Bulleromyces clade within the order Tremellales, with C. laurentii as their closest described relative. The novel strains showed 1.6 and $7.5 \%$ divergence in the D1/D2 domain of the LSU rDNA and ITS regions, respectively, with respect to $C$. laurentii. The divergence from other species was more than $3 \%$ for the D1/D2 domain and more than $9 \%$ for the ITS region. On the basis of the phenotypic and molecular data, strains $S-15 L^{\top}$ and $3-C 1$ represent a novel species within the genus Cryptococcus, for which the name Cryptococcus rajasthanensis sp. nov. is proposed. The type strain is $\mathrm{S}-15 \mathrm{~L}^{\top}\left(=\right.$ MTCC $7075^{\top}=$ CBS $\left.10406^{\top}\right)$.
\end{abstract}

The basidiomycetous yeast genus Cryptococcus Vuillemin is characterized by the following features: a lack of sexual structures and ballistoconidia, the utilization of D-glucuronate, the absence of fermentation, the presence of xylose in cell hydrolysates and positive reactions in the diazonium blue B and urease tests (Fell \& Statzell-Tallman, 1998). The genus is known to be polyphyletic, containing members of the orders Tremellales, Filobasidiales, Trichosporonales and Cystofilobasidiales (Fell et al., 2000; Scorzetti et al., 2002). The taxonomic heterogeneity of two so-called 'ubiquitous' Cryptococcus species, Cryptococcus albidus and Cryptococcus laurentii, was reported in some earlier studies (Vancanneyt et al., 1994; Takashima \& Nakase, 1999; Fonseca et al., 2000; Sugita et al., 2000). Sequence analysis of the D1/D2 domain of the large-subunit (LSU) rDNA and the internal

Abbreviations: ITS, internal transcribed spacer; LSU, large subunit.

The GenBank/EMBL/DDBJ accession numbers for the sequences of the D1/D2 domain of the LSU rDNA and the ITS region of strain S$15 L^{\top}$ are AM262324 and AM262325, respectively, and that for the combined D1/D2 domain and ITS region sequence of strain 3-C1 is AM262981.

A neighbour-joining phylogenetic tree for strains S-15L $\mathrm{L}^{\top}$ and $3-\mathrm{C} 1$ and related species based on LSU rDNA sequences is available as a supplementary figure in IJSEM Online. transcribed spacer (ITS) region has resulted in the description of several novel Cryptococcus species that were previously thought to be members of either $C$. albidus or $C$. laurentii on the basis of the results of phenotypic analyses (Takashima et al., 2003; Middelhoven, 2005; Golubev et al., 2006).

Members of the genus Cryptococcus are heterogeneous in terms of their nutritional abilities and have been isolated from diverse habitats. However, there are only few reports of Cryptococcus species having been isolated from flowers. Cryptococcus gattii, an emerging pathogen of humans, was isolated from different parts of Eucalyptus trees, including the flowers (Chakrabarti et al., 1997; Ellis \& Pfeiffer, 1990). Cryptococcus species were found to be the predominant yeasts (23 out of 69) in flowers in Germany (Herzberg et al., 2002); most of them were related to Cryptococcus victoriae, followed by Cryptococcus diffluens and C. albidus. Only one strain (CBS 9007) was shown to be related to C. laurentii. Hong et al. (2002) isolated four strains related to $C$. victoriae and one related to Cryptococcus luteolus from flowers in Korea.

During a survey of yeasts from flowers from the Ganganagar and Rawatbhata regions of Rajasthan State in India, more 
than 70 yeast strains belonging to various genera were isolated. Conventional methods and sequencing of the D1/ D2 domain of the LSU rDNA suggested that five isolates were related to members of the genus Cryptococcus. Two isolates $\left(\mathrm{S}-15 \mathrm{~L}^{\mathrm{T}}\right.$ and $\left.3-\mathrm{C} 1\right)$ were related to C. laurentii, two isolates (S-1C and S-1D) were related to C. victoriae and one strain (2-B2) was identified as C. diffluens. Strain $\mathrm{S}-15 \mathrm{~L}^{\mathrm{T}}$ was isolated from an inflorescence of Digera sp., and strain 3-C1 was isolated from a different locality (about $1000 \mathrm{~km}$ away from the first location) from an inflorescence of Andrographis echioides (see Table 1). On the basis of conventional morphological and physiological tests, these strains were shown to belong to the genus Cryptococcus. No hyphae or pseudohyphae were observed on cornmeal agar even after 30 days. No sexual structures or ballistoconidia were observed on cornmeal agar, $2 \%$ malt agar, $5 \%$ malt agar or potato dextrose agar (PDA) after 1 month. Molecular characterization of these yeast strains through sequencing of the D1/D2 domains of LSU rDNAs and the ITS regions suggested that $S-15 \mathrm{~L}^{\mathrm{T}}$ and $3-\mathrm{C} 1$ are strains of the same species and confirmed their close relationship with C. laurentii. It has been suggested that basidiomycetous yeast strains that differ by more than $1 \%$ sequence divergence in the D1/D2 domain and the ITS region can be considered to be strains of different species (Fell et al., 2000; Scorzetti et al., 2002). Strains S-15L $\mathrm{L}^{\mathrm{T}}$ and 3-C1 differ from C. laurentii by $1.6 \%$ sequence divergence in the D1/D2 domain and $7.5 \%$ variation in the ITS region, and also showed six differences in physiological tests. All of these data support the assignment of these strains to a novel species of the genus Cryptococcus.

Strains $\mathrm{S}-15 \mathrm{~L}^{\mathrm{T}}$ and $3-\mathrm{C} 1$ were isolated from $1 \mathrm{~g}$ samples of inflorescences homogenized in $9.0 \mathrm{ml}$ sterile water; serial dilutions were made and spread on yeast extract/peptone/ dextrose (YEPD) plates, supplemented with chloramphenicol $\left(50 \mathrm{mg} \mathrm{l}^{-1}\right)$ and streptomycin $\left(30 \mathrm{mg} \mathrm{l}^{-1}\right)$ to suppress bacterial growth. The strains were isolated from YEPD plates at $25^{\circ} \mathrm{C}$ after 4 days incubation, purified, stored in $10 \%$ glycerol at $-70^{\circ} \mathrm{C}$ and in liquid nitrogen for long-term maintenance. The methods used to determine the morphological, physiological and biochemical properties were performed as described by Yarrow (1998). The type strain of C. laurentii, MTCC $2898^{\mathrm{T}}\left(=\mathrm{CBS} 139^{\mathrm{T}}\right)$, was used for comparison of the phenotypic characteristics. Assays for observation of sexual structures were performed on cornmeal agar, $2 \%$ malt agar, $5 \%$ malt agar and PDA, with plates being incubated at 20 and $25^{\circ} \mathrm{C}$ for 1 month in pure and mixed cultures.

Isolation of genomic DNA and PCR amplification of ITS regions and D1/D2 domains of LSU rDNAs were done as described previously (Prasad et al., 2005). The amplified fragments were purified by using the QIAquick gel extraction kit (Qiagen) according to the manufacturer's instructions. Direct sequencing of gel-purified PCR products was performed with the ABI BigDye terminator cycle sequencing ready reaction kit (Applied Biosystems). Both strands of the PCR product were sequenced. Sequencing reactions were purified by using ethanol and $125 \mathrm{mM}$ EDTA precipitation. Processing of the samples for loading onto an ABI $3130 x l$ Genetic Analyzer (Applied Biosystems) was performed according to the instructions of the manufacturer. A sequence-similarity search was done using GenBank BLASTN (Altschul et al., 1997). Sequences of closely related taxa were retrieved and aligned using the CLUSTAL $\mathrm{X}$ program (Thompson et al., 1997). For the neighbourjoining analysis (Saitou \& Nei, 1987), distances between the sequences were calculated using Kimura's two-parameter model (Kimura, 1980). Bootstrap analysis was performed to assess the confidence limits of the branching (Felsenstein, 1985).

Strains $\mathrm{S}-15 \mathrm{~L}^{\mathrm{T}}$ and $3-\mathrm{C} 1$ differ from $C$. laurentii in six physiological tests. The novel strains assimilate nitrite, citrate (weakly), erythritol (weakly) and sorbose (weakly), produce starch-like compounds (weakly) and cannot grow at $35^{\circ} \mathrm{C}$, whereas $C$. laurentii assimilates only erythritol (not nitrite, citrate or sorbose), shows pronounced production of starch-like compounds, and shows growth at $35^{\circ} \mathrm{C}$. The novel strains showed more than six phenotypic differences with respect to other related species (Table 2). Strains S$15 \mathrm{~L}^{\mathrm{T}}$ and $3-\mathrm{C} 1$ have identical sequences in D1/D2 domain and differ by one base substitution in the ITS region, suggesting that they are strains of the same species. Sequences of related species were retrieved from the nucleic acid databases and phylogenetic trees were constructed separately for the ITS region (data not shown), the D1/D2 domain of the LSU rDNA (see Supplementary Fig. S1 available in IJSEM Online) and also the combination of the ITS and D1/D2 domain (Fig. 1). Phylogenetic analysis showed that strain $\mathrm{S}-15 \mathrm{~L}^{\mathrm{T}}$ belongs to the Bulleromyces clade

Table 1. Strains used in this study

\begin{tabular}{|lcc|}
\hline Strain & Source and date of isolation & Location \\
\hline S- $15 \mathrm{~L}^{\mathrm{T}}\left(=\mathrm{MTCC} 7075^{\mathrm{T}}=\mathrm{CBS} 10406^{\mathrm{T}}\right)$ & Inflorescence of Digera sp. & Sunderpura, Rajasthan, India \\
& $($ October 2004) & $\left(29^{\circ} 55^{\prime} 18^{\prime \prime} \mathrm{N} 73^{\circ} 51^{\prime} 39^{\prime \prime} \mathrm{E}\right)$ \\
$3-\mathrm{C} 1(=\mathrm{MTCC} 7847)$ & Inflorescence of A. echioides & Rawatbhata, Rajasthan, India \\
& $($ September 2005) & $\left(25^{\circ} 10^{\prime} 34^{\prime \prime} \mathrm{N} 75^{\circ} 49^{\prime} 51^{\prime \prime} \mathrm{E}\right)$ \\
C. laurentii CBS $139^{\mathrm{T}}\left(=\mathrm{MTCC} 2898^{\mathrm{T}}\right)$ & Palm wine (not known) & The Congo \\
\hline
\end{tabular}


Table 2. Physiological characteristics that differentiate strains $\mathrm{S}-15 \mathrm{~L}^{\top}$ and $3-\mathrm{C} 1$ from closely related strains

Strains: 1, C. rajasthanensis sp. nov. $\mathrm{S}-15 \mathrm{~L}^{\mathrm{T}}$ (strain $3-\mathrm{C} 1$ gave identical results); 2, C. laurentii CBS $139^{\mathrm{T}} ; 3$, Cryptococcus sp. CBS 7140; 4, C. aureus CBS $318^{\mathrm{T}}$; 5, Bullera japonica CBS $2013^{\mathrm{T}} ; 6$, C. nemorosus VKM Y-2906 ${ }^{\mathrm{T}}$. Symbols: + , positive; -, negative; $\mathrm{w}$, weak; d, delayed; s, slow.

\begin{tabular}{|lcccccc|}
\hline Characteristic & $\mathbf{1}$ & $\mathbf{2}$ & $\mathbf{3}$ & $\mathbf{4}$ & $\mathbf{5}$ & $\mathbf{6}$ \\
\hline Assimilation of: & & & & & & \\
L-Sorbose & $\mathrm{w}$ & - & - & - & + & $\mathrm{w}$ \\
Glycerol & - & - & + & $\mathrm{w}$ & $\mathrm{d}$ & $\mathrm{s}$ \\
Ethanol & $\mathrm{w}$ & $\mathrm{w}$ & + & - & - & + \\
Nitrite & + & - & - & - & - & - \\
Citrate & $\mathrm{w}$ & - & + & - & + & + \\
Erythritol & $\mathrm{w}$ & + & + & - & + & - \\
Growth at: & & & & & & \\
$35^{\circ} \mathrm{C}$ & - & + & + & - & - & - \\
$37^{\circ} \mathrm{C}$ & - & - & + & - & - & - \\
Starch formation & $\mathrm{w}$ & + & + & + & + & + \\
\hline
\end{tabular}

in the Tremellales sensu Scorzetti et al. (2002), clustering with $C$. laurentii as its closest relative (Fig. 1). The topologies of both the D1/D2 and combined ITS and D1/ D2 trees were similar, showing only minor differences. In the D1/D2 tree, Cryptococcus aureus and Cryptococcus flavescens appeared in a cluster along with Cryptococcus nemorosus, Cryptococcus perniciosus, Cryptococcus taeanensis and Bullera japonica, whereas they appear to be basal to all related species in the combined tree. This clade (demarcated by Cryptococcus nemorosus and Cryptococcus flavescens) is supported by $100 \%$ bootstrap values in this tree. Sequence analysis showed that strain $\mathrm{S}-15 \mathrm{~L}^{\mathrm{T}}$ differs from C. laurentii by $1.6 \%$ divergence ( 9 substitutions) in the D1/D2 domain of the LSU rDNA, and by $7.5 \%$ divergence in the combined ITS1 and ITS2 sequences (10 substitutions and 2 indels in ITS1; 8 substitutions and 2 indels in ITS2). On the basis of the D1/D2-domain sequence analysis, other species related to the novel strains are C. aureus (2.9\% divergence), Bullera japonica (3.1\%), C. nemorosus (3.2\%), C. perniciosus (3.6\%), C. flavescens (3.6\%), Cryptococcus cellulolyticus (4.4\%) and Bullera pseudoalba (4.4\%). Variation in the combined sequences of ITS1 and ITS2 (excluding 5.8S rDNA) was more than $9 \%$ with respect to all other related species.

An understanding of the role and diversity of basidiomycetous yeast species in natural habitats has been slow to develop because of difficulties associated with identification procedures (Fell et al., 2000). As a consequence, some yeasts, such as C. laurentii, are considered to be ubiquitous (de Azeredo et al., 1998; Saldanha-da-Gama et al., 1997; Slavikova \& Vadkertiova, 2000); this could be due to incorrect delineation of this species, as several tests used for its identification give variable results (Fell \&

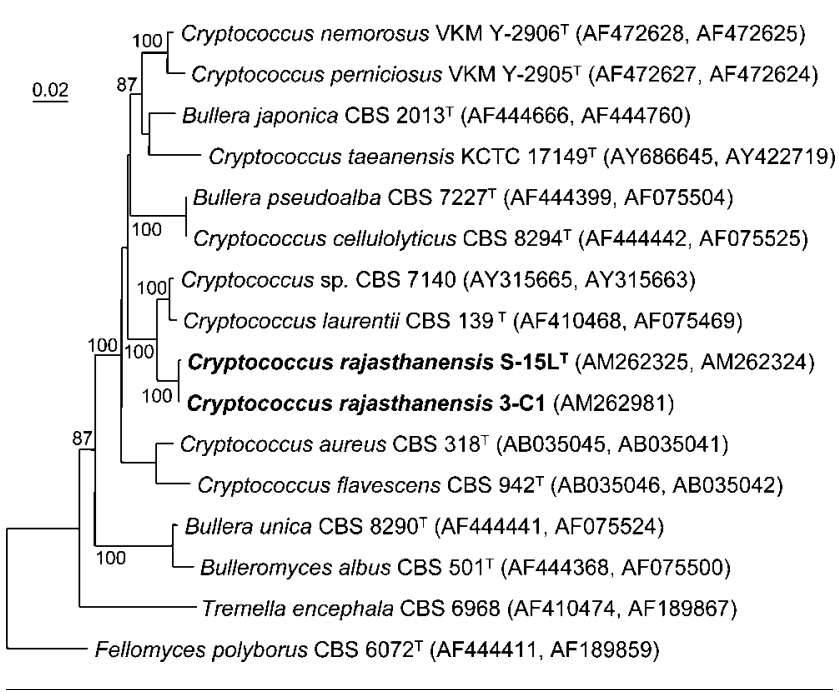

Fig. 1. Neighbour-joining tree of strains $S-15 L^{\top}$ and $3-C 1$ and related species, based on sequences of the ITS region of the rDNA cluster and the D1/D2 domain of LSU rDNA. Evolutionary distances were calculated according to Kimura (1980). Numbers at nodes are bootstrap values from 100 replicate samplings; values less than 70 are not shown. Fellomyces polyborus CBS $6072^{\top}$ was used as the outgroup. Bar, $2 \%$ variation.

Statzell-Tallman, 1998; Barnett et al., 2000). Interestingly, it is also difficult to distinguish $C$. laurentii from $C$. cellulolyticus, Cryptococcus flavus, Cryptococcus humicola and Cryptococcus hungaricus on the basis of physiological characteristics (Barnett et al., 2000). After a comprehensive study of all basidiomycetous yeasts, Fell et al. (2000) suggested that strains that differ in two or more nucleotides in the D1/D2 domain of the LSU rDNA may represent different taxa. These authors also showed that biologically distinct species that could not be separated using D1/D2 analysis could be differentiated using ITS sequence analysis. Scorzetti et al. (2002) recommended a combined sequence analysis (the D1/D2 domain and the ITS region) for species identification of basidiomycetous yeasts. Sugita et al. (2000) reported genetic diversity in the ITS and D1/D2 regions among clinical isolates of $C$. laurentii: ten isolates examined in that study were found to belong to seven different species. Three novel Cryptococcus species that were previously considered as synonyms of $C$. laurentii were reinstated on the basis of sequencing of the $18 \mathrm{~S} \mathrm{rDNA}$ and the D1/D2 region of the LSU rDNA (Takashima et al., 2003). Similarly, strains CBS $9604^{\mathrm{T}}$ and CBS 7140, which could not be distinguished from $C$. laurentii on the basis of phenotypic characteristics (Kurtzman \& Fell, 1998; Barnett et al., 2000), were shown to differ from $C$. laurentii in terms of ITS and D1/D2 sequences. Strain CBS $9604^{\mathrm{T}}$ was recently described as Cryptococcus allantoinivorans (Middelhoven, 2005) and CBS 7140 also appears to represent a novel species, as it differs from the type strain of C. laurentii $\left(\mathrm{CBS} 139^{\mathrm{T}}\right.$ ) by one base substitution in the D1/D2 domain and ten base 
substitutions in ITS region. Strain S- $15 \mathrm{~L}^{\mathrm{T}}$ differs from CBS 7140 by eight substitutions in the D1/D2 domain, by eight substitutions and one indel in ITS1, and by seven substitutions and one indel in ITS2. Comparisons with all of the described species of the C. laurentii complex show that the two novel yeast strains $\left(\mathrm{S}-15 \mathrm{~L}^{\mathrm{T}}\right.$ and $\left.3-\mathrm{C} 1\right)$ reported in this investigation are the closest relatives of $C$. laurentii; however, they differ from $C$. laurentii in six physiological tests, show more than $1 \%$ divergence in the D1/D2 domain and show $7.5 \%$ divergence in combined ITS1 and ITS2 regions. These data strongly support the assignment of S$15 \mathrm{~L}^{\mathrm{T}}$ and 3-C1 to a novel species of the genus Cryptococcus, for which we propose the name Cryptococcus rajasthanensis sp. nov.

\section{Latin description of Cryptococcus rajasthanensis P. Saluja et G. S. Prasad sp. nov.}

In liquido YEPD post 2 dies $25^{\circ} \mathrm{C}$ cellulae ovales, 3.5-6.5 × 3.5-5.5 $\mu \mathrm{m}$. Coloniae dilute flavae, viscosae, margine integra; post 20 dies luteo-bubalinae. In agaro farinae zeae mycelium non formantur. Teleomorphe ignota. Substrata carbonica assimilata: D-galactosum, D-glucosaminum, Larabinosum, D-arabinosum, D-ribosum, D-xylosum, L-rhamnosum, sucrosum, maltosum, methyl $\alpha$-D-glucosidum, melibiosum, cellobiosum, salicinum, arbutinum, raffinosum, lactosum, melezitosum, erythritolum (parce), ribitolum, L-arabinitolum, xylitolum, D-glucitolum, D-mannitolum, myo-inositolum, galactitolum, $\mathrm{N}$-acetylglucosaminum, 2keto-D-gluconatum, D-glucuronatum, acidum D-gluconicum $\left(\mathrm{Na}^{+}\right), \quad \mathrm{D}$-glucono-1,5-lactonum, trehalosum, citratum (parce), L-sorbosum (parce), ethanolum (parce), inulinum (parce), succinatum (parce), neque amylum, methanolum, DL-lactatum, glycerolum. Substrata nitrogenica assimilata: nitritum, cadaverinum, lysinum, creatinum (parce), ethylaminum; neque nitratum. Non fermentat neque crescit $0.01 \mathrm{vel}$ $0.1 \%$ cycloheximido addito. Acidum aceticum haud formatum. 50 vel $60 \%$ glucosii addito haud crescit. Substantia amyli similis parce formatur. Reactiones Diazonium caeruleum B et ureasii positivae. 25 et $30^{\circ} \mathrm{C}$ crescit, neque $35^{\circ} \mathrm{C}$. Isolatus ex flores, in Rajasthan, India. Typus S-15L $\mathrm{L}^{\mathrm{T}}$ (=MTCC $\left.7075^{\mathrm{T}}=\mathrm{CBS} 10406^{\mathrm{T}}\right)$. Conservatur in Microbial Type Culture Collection and Gene Bank, Chandigarh, India.

\section{Description of Cryptococcus rajasthanensis $P$. Saluja \& G. S. Prasad sp. nov.}

Cryptococcus rajasthanensis (ra.jas.than.en'sis. N.L. nom. masc. adj. rajasthanensis referring to Rajasthan State in India, from which the first strains were isolated).

After 2 days growth in YEPD broth at $25^{\circ} \mathrm{C}$, cells are oval, 3.5-6.5 $\times 3.5-5.5 \mu \mathrm{m}$ (Fig. 2). Aerobic growth results in pale-yellow, circular colonies with entire margins. Colonies are viscous in consistency and turn yellow-tan after 20 days incubation at $25^{\circ} \mathrm{C}$. Neither mycelium nor pseudomycelium is observed in Dalmau plate culture on cornmeal agar or on PDA, even after 30 days. No sexual structures are

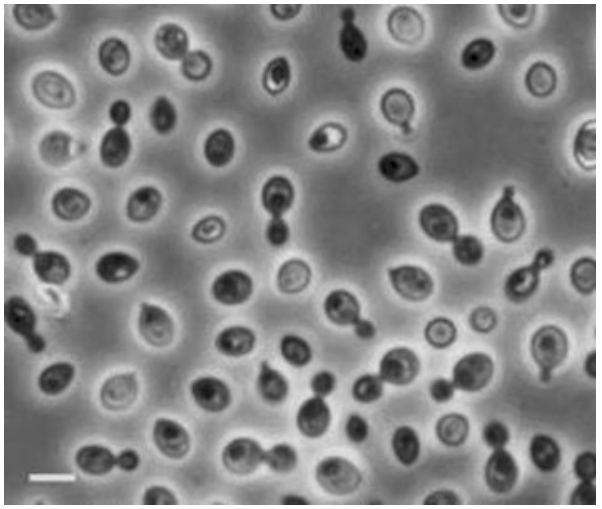

Fig. 2. Cell morphology of strain $S-15 L^{\top}$ after $48 \mathrm{~h}$ in YEPD broth. Bar, $5 \mu \mathrm{m}$.

observed in mixed or pure cultures plated on cornmeal agar, $2 \%$ malt agar, $5 \%$ malt agar (Fig. 2) and PDA. Assimilation of carbon compounds is as follows: D-galactose, Dglucosamine, L-arabinose, D-arabinose, D-ribose, D-xylose, L-rhamnose, sucrose, maltose, methyl $\alpha$-D-glucoside, melibiose, cellobiose, salicin, arbutin, raffinose, lactose, melezitose, erythritol (weakly), ribitol, L-arabinitol, xylitol, D-glucitol, D-mannitol, myo-inositol, galactitol, $\mathrm{N}$-acetylglucosamine, 2-keto-D-gluconate, D-glucuronate, D-gluconic acid sodium salt, D-glucono-1,5 lactone, $\alpha, \alpha$-trehalose, citrate (weakly), L-sorbose (weakly) and succinate (weakly), inulin (weakly), ethanol (weakly) are assimilated, but starch, methanol, DL-lactate and glycerol are not assimilated. Nitrite, cadaverine, lysine, creatine (weakly) and ethylamine are assimilated. Nitrate is not assimilated. Fermentation is absent, and no growth occurs in the presence of 0.01 or $0.1 \%$ cycloheximide. Acetic acid production is absent. No growth occurs on 50 or $60 \%$ glucose. Production of starchlike compounds is weakly positive. Reactions with diazonium blue $\mathrm{B}$ and for urease are positive. Grows at 25 and $30^{\circ} \mathrm{C}$, but not at $35^{\circ} \mathrm{C}$.

The type strain, $\mathrm{S}-15 \mathrm{~L}^{\mathrm{T}}$ (deposited in the Microbial Type Culture Collection and Gene Bank, Chandigarh, India, as MTCC $7075^{\mathrm{T}}$ and in the Centraalbureau voor Schimmelcultures, Utrecht, Netherlands, as CBS $10406^{\mathrm{T}}$ ), and strain 3-C1 were isolated from inflorescences of plants from Rajasthan State in India.

\section{Acknowledgements}

This study was supported by the Council of Scientific and Industrial Research (India) and the Department of Biotechnology, Government of India, in the form of a grant to the Microbial Type Culture Collection and Gene Bank. P.S. is a recipient of a senior research fellowship from the Council of Scientific and Industrial Research. The authors are grateful to Mr Gurdeep, Punjab University (Chandigarh, India) for his help in identifying the plants and to Mr Paramjit for his help with the physiological characterization of the strains. 


\section{References}

Altschul, S. F., Madden, T. L., Schaffer, A. A., Zhang, J., Zhang, Z., Miller, W. \& Lipman, D. J. (1997). Gapped BLAST and PSI-BLAST: a new generation of protein database search programs. Nucleic Acids Res 25, 3389-3402.

Barnett, J. A., Payne, R. W. \& Yarrow, D. (2000). Yeasts: Characteristics and Identification, 3rd edn. Cambridge: Cambridge University Press.

Chakrabarti, A., Jatana, M., Kumar, P., Chatha, L., Kaushal, A. \& Padhye, A. A. (1997). Isolation of Cryptococcus neoformans var. gattii from Eucalyptus camaldulensis in India. J Clin Microbiol 35, 3340-3342.

de Azeredo, L. A., Gomes, E. A., Mendonca-Hagler, L. C. \& Hagler, A. N. (1998). Yeast communities associated with sugarcane in Campos, Rio de Janeiro, Brazil. Int Microbiol 1, 205-208.

Ellis, D. H. \& Pfeiffer, T. J. (1990). Natural habitat of Cryptococcus neoformans var. gattii. J Clin Microbiol 28, 1642-1644.

Fell, J. W. \& Statzell-Tallman, A. (1998). Cryptococcus Vuillemin. In The Yeasts, a Taxonomic Study, 4th edn, pp. 742-767. Edited by C. P. Kurtzman \& J. W. Fell. Amsterdam: Elsevier.

Fell, J. W., Boekhout, T., Fonseca, A., Scorzetti, G. \& StatzellTallman, A. (2000). Biodiversity and systematics of basidiomycetous yeasts as determined by large-subunit rDNA D1/D2 domain sequence analysis. Int J Syst Evol Microbiol 50, 1351-1371.

Felsenstein, J. (1985). Confidence limits on phylogenies: an approach using the bootstrap. Evolution 39, 783-791.

Fonseca, A., Scorzetti, G. \& Fell, J. W. (2000). Diversity in the yeast Cryptococcus albidus and related species as revealed by ribosomal DNA sequence analysis. Can J Microbiol 46, 7-27.

Golubev, W. I., Sampaio, J. P., Alves, L. \& Golubeva, E. W. (2006). Cryptococcus silvicola nov. sp. from nature reserves of Russia and Portugal. Antonie van Leeuwenhoek 89, 45-51.

Herzberg, M., Fischer, R. \& Titze, A. (2002). Conflicting results obtained by RAPD-PCR and large-subunit rDNA sequences in determining and comparing yeast strains isolated from flowers: a comparison of two methods. Int J Syst Evol Microbiol 52, 1423-1433.

Hong, S. G., Lee, K. H. \& Bae, K. S. (2002). Diversity of yeasts associated with natural environments in Korea. J Microbiol 40, 55-62.

Kimura, M. (1980). A simple method for estimating evolutionary rates of base substitutions through comparative studies of nucleotide sequences. J Mol Evol 16, 111-120.

Kurtzman, C. P. \& Fell, J. W. (editors) (1998). The Yeasts, a Taxonomic Study, 4th edn. Amsterdam: Elsevier.
Middelhoven, W. J. (2005). Cryptococcus allantoinivorans sp. nov., an anamorphic basidiomycetous yeast (Tremellales) physiologically resembling other species of the Cryptococcus laurentii complex that degrade polysaccharides and $\mathrm{C} 2$ compounds. Antonie van Leeuwenhoek 87, 101-108.

Prasad, G. S., Mayilraj, S., Sood, N., Singh, V., Biswas, K. \& Lal, B. (2005). Candida digboiensis sp. nov., a novel anamorphic yeast species from an acidic tar sludge-contaminated oilfield. Int J Syst Evol Microbiol 55, 967-972.

Saitou, N. \& Nei, M. (1987). The neighbor-joining method: a new method for reconstructing phylogenetic trees. Mol Biol Evol 4, 406-425.

Saldanha-da-Gama, A., Malfeito-Ferreira, M. \& Loureiro, V. (1997). Characterization of yeasts associated with Portuguese pork-based products. Int J Food Microbiol 37, 201-207.

Scorzetti, G., Fell, J. W., Fonseca, A. \& Statzell-Tallman, A. (2002). Systematics of basidiomycetous yeasts: a comparison of large subunit D1/D2 and internal transcribed spacer rDNA regions. FEMS Yeast Res 2, 495-517.

Slavikova, E. \& Vadkertiova, R. (2000). The occurrence of yeasts in the forest soils. J Basic Microbiol 40, 207-212.

Sugita, T., Takashima, M., Ikeda, R., Nakase, T. \& Shinoda, T. (2000). Intraspecies diversity of Cryptococcus laurentii as revealed by sequences of internal transcribed spacer regions and 28S rRNA gene and taxonomic position of Cryptococcus laurentii clinical isolates. J Clin Microbiol 38, 1468-1471.

Takashima, M. \& Nakase, T. (1999). Molecular phylogeny of the genus Cryptococcus and related species based on the sequences of $18 \mathrm{~S}$ rDNA and internal transcribed spacer regions. Microbiol Cult Coll 15, 33-45.

Takashima, M., Sugita, T., Shinoda, T. \& Nakase, T. (2003). Three new combinations from the Cryptococcus laurentii complex: Cryptococcus aureus, Cryptococcus carnescens and Cryptococcus peneaus. Int J Syst Evol Microbiol 53, 1187-1194.

Thompson, J. D., Gibson, T. J., Plewniak, F., Jeanmougin, F. \& Higgins, D. G. (1997). The CLUSTAL_X windows interface: flexible strategies for multiple sequence alignment aided by quality analysis tools. Nucleic Acids Res 25, 4876-4882.

Vancanneyt, M., Coopman, R., Tytgat, R., Hennebert, G. L. \& Kersters, K. (1994). Whole-cell protein patterns, DNA base compositions and coenzyme $\mathrm{Q}$ types in the yeast genus Cryptococcus Kützing and related taxa. Syst Appl Microbiol 17, 65-75.

Yarrow, D. (1998). Methods for the isolation, maintenance and identification of yeasts. In The Yeasts, a Taxonomic Study, 4th edn, pp. 77-100. Edited by C. P. Kurtzman \& J. W. Fell. Amsterdam: Elsevier. 